\title{
Flavored sisal ropes as environmental enrichment for nursery piglets
}

\author{
Janaina Cristina da Silva Maciel de Souza ID. Laya Kannan Silva Alves ID. Eduarda Buck Bernardes Guimarães (iD. \\ Gabriela dos Santos Madella (D. Bruno Braga Carnino - Emilye Izabele Cristina de Moraes ID. Pedro Ventura Dibo • \\ Nicolas Carvalho Braga • Johnny Maciel de Souza ID. Bo Zhou ID. Cesar Augusto Pospissil Garbossa (iD)
}

JCSM Souza - LKS Alves - EBB Guimarães - GS Madella - BB Carnino - EIC Moraes - PV Dibo - NC Braga - JM Souza - CAP Garbossa (Corresponding author) Swine Research Laboratory, Department of Animal Nutrition and Production, School of Veterinary Medicine and Animal Sciences, University of São Paulo (USP), Pirassununga, São Paulo, 13635-900, Brazil.

\section{B Zhou}

Nanjing Agricultural University, Nanjing, Jiangsu, China.

email: cgarbossa@usp.br

\section{Received: August 17, 2020 - Accepted: September 08, 2020 • Published Online: September 16, 2020}

\begin{abstract}
The objective of the present study was to evaluate the behavior of piglets in the nursery phase in the presence of pure sisal ropes, soaked with different flavors as a means of environmental enrichment. Sixty-four piglets with 35 days of age in the nursery phase were used, piglets were randomly distributed in a completely randomized design in 16 pens, with four animals in each pen and there was no separation of pens by group. Three treatments were used: Pure rope (PR) which was considered the control of the pen, rope soaked in vanilla essence and sugar (SV), and rope soaked in coffee (SC). An ethogram was prepared for observations of the following behavioral parameters, eating, drinking, urinating, defecating, lying down, standing, playful, and others. The parameters were measured every 10 minutes in a total of three daily assessments with two hours each for a period of three days. There was a greater preference of piglets for the SV rope with a percentage of $63.2 \%$ in the observations of the interactions. A possible justification for the result is the fact that this rope is the most palatable for piglets since piglets prefer sweet tastes. The PR rope aroused curiosity in the piglets, with a percentage of observations of $21.4 \%$. Therefore, the use of equipment flavored with sweet vanilla taste is promising as a means of environmental enrichment, being more interesting to piglets.
\end{abstract}

Keywords: flavor, natural behavior, swine, welfare

\section{Introduction}

Pigs are among the most numerous farmed animals worldwide and nearly all commercial pig farming is carried out intensively (FAO 2019). In Brazil, as in the rest of the globe, pig production is most intensive, and animals are raised in all production phases (Padilha-Boareto et al 2020). Such intensive systems are characterized by housing in pens with a high density of animals, and in this scenario, it is common to observe the expression of stereotyped behaviors as a response to the inability to express their natural behavior (Kelly et al 2000; Scott el al 2006; Foppa et al 2018; Padilha-Boareto et al 2020).

In the face of new demands of the international market and changes in consumers profile, pig farmers must adapt their production systems to improve animal well-being (Foppa et al 2018). Constantly, researchers and pig farmers are asked by these consumers about how the welfare of pigs has been considered throughout the process of raising these animals. Therefore, studies with environmental enrichment correlated to the behavior of pigs are extremely valuable to improve the welfare and implementation of these technologies in the productive system.

It is known that when pigs are not able to exert their natural behavior, they target their investigative behavior to explore the confinement environment and the other pigs in the pen (Scott et al 2006; Foppa et al 2018). Environmental enrichment, besides, to be an alternative to control undesired behaviors of pigs, improves the conditions for raising these animals allowing them to express their typical behavior, providing welfare for animals (Van de Weerd and Ison 2019).

According to Foppa et al (2014), the use of environmental enrichment can improve the welfare of animals by allowing them to express natural behaviors of the species. Besides, studies have shown that pigs prefer substrates to toys and that materials that were destructible and had edible parts 
are also preferred by the pigs (Van de Weerd et al 2003; Foppa et al 2018).

According to Foppa et al (2018), the efficacy of any type of environmental enrichment depends on its capacity to stimulate a certain behavior of the animals. Bezerra et al (2019) concluded that the use of sisal rope as a means of environmental enrichment stimulated positive behaviors in piglets, however, the use of pet bottles and chains resulted in negative effects such as stress, lipid peroxidation, and reduced body weight gain.

It is known that pigs have a great capacity to taste and, consequently, the sense of smell is also very sharp, therefore, are believed that piglets prefer sweeter flavors (Duengelhoef 2010). It is recognized that piglets eat more and consequently improve weight gain when fed diets containing sweet additives such as sucrose, lactose, dextrose, or artificial sweeteners (Mcdonald et al 1987; Munro et al 2000; Sterk et al 2008). However, regarding the preference for aroma, the works are not conclusive, thus, it is interesting to associate the technologies of environmental enrichment with the sensation of taste and odor, allowing a greater interest of animals with the object of enrichment and thereby making it more effective.

Therefore, the objective of this study was to evaluate the behavior of piglets in the nursery phase in the presence of pure sisal ropes, soaked with different flavors as a means of environmental enrichment.

\section{Materials and Methods}

\section{Ethics statement}

Animal procedures were consistent with the guide for the Care and Use of Animals in Agricultural Research and Teaching (FASS 2010).

\section{Location and installations}

The experiment was carried out in the nursery facilities of the Swine Research Laboratory, of the School of Veterinary Medicine and Animal Science of the University of São Paulo, located at Pirassununga, São Paulo, Brazil. The piglets had ad libitum access to water and a nursery commercial diet.

\section{Experimental design}

For this study, 64 piglets with 35 days of age were used in the nursery phase, randomly distributed in a completely randomized design in 16 pens (4 piglets/pen), all 16 pens received the three treatments (three types of ropes). For behavioral analysis of piglets in the presence of ropes as a means of environmental enrichment, $30 \mathrm{~cm}$ length sisal ropes tied with the aid of plastic clamps arranged on a nylon rope positioned and tied over each pen were used (Figure 1), all the ropes were presented at the same time for the piglets. The treatments used were: Pure rope (PR) that was the rope with no flavors added; Rope soaked in vanilla essence and sugar (SV); and Rope soaked in coffee (SC). An ethogram was prepared for observations of the following behavioral parameters, eating (E), drinking (D), urinating (U), defecating (DF), lying down (LD), standing (ST), playful (P), and others (O). The parameters were measured every 10 minutes in a total of three daily assessments ( $7 \mathrm{~h}$ to $9 \mathrm{~h}, 11 \mathrm{~h}$ to $13 \mathrm{~h}$, and 16 to $18 \mathrm{~h})$, with two hours each for a period of three days $(29,30$ April, and 1 May 2019). The observations were made daily, with the help of spreadsheets formulated with the usual behavior of the piglets mentioned above. Care was taken to avoid, as far as possible, the observer from interfering in the animals' behavior.

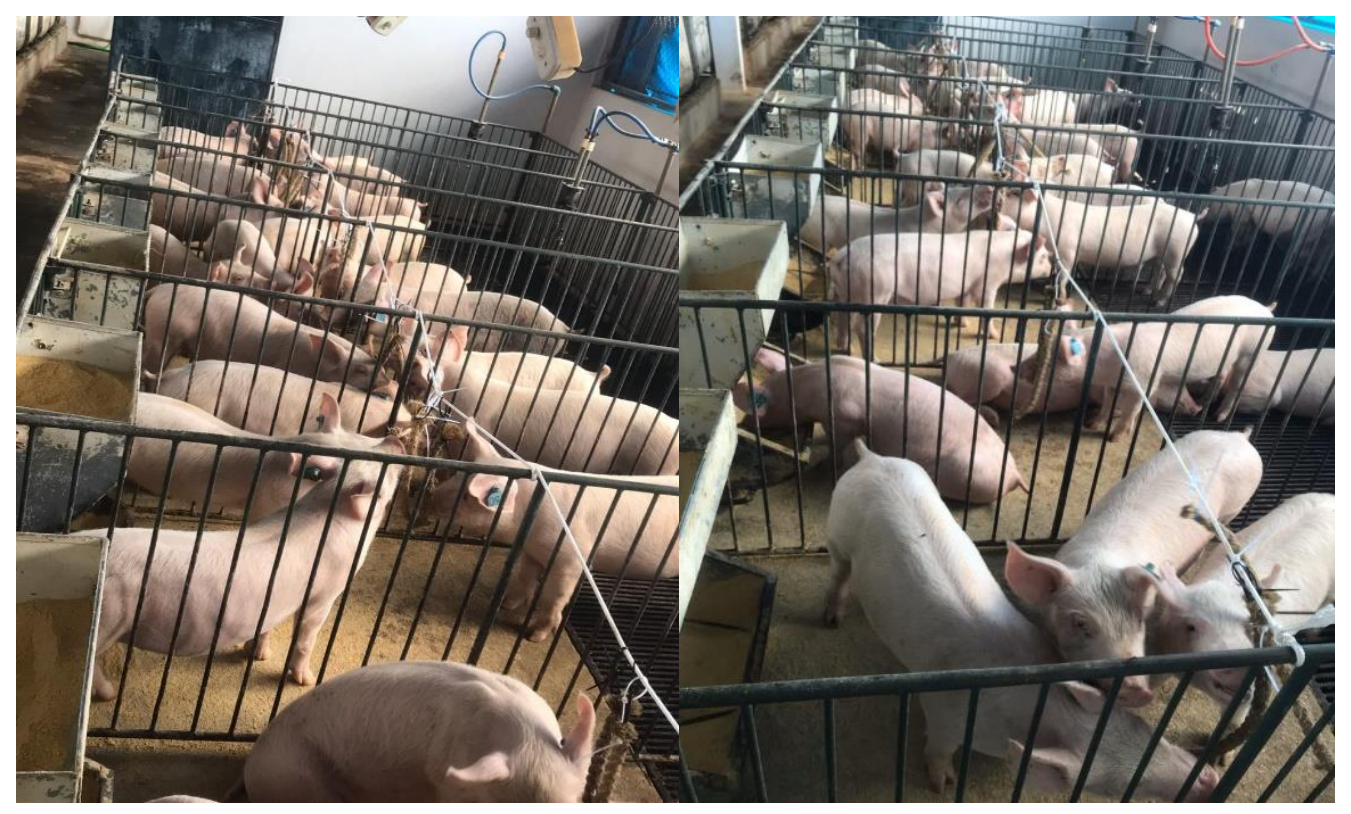

Figure 1 Sisal ropes were provided to the pigs positioned over each pen. 


\section{Statistical Analysis}

The data were analyzed using the SAS 9.4 (SAS Institute 2013) software, the data were evaluated to check the homogeneity of the variances (Levene test) and normality of the residuals (Kolmogorov-Smirnov). Subsequently, the data were submitted to one-way variance analysis (ANOVA), followed by the Tukey test to assess the difference between the ropes. The results were expressed followed by the standard deviation and were considered significant with $P \leq 0.05$.

\section{Results}

Observations of piglet behavior concerning the presence of sisal ropes PR, SV, and SC are shown in Table 1. The rope soaked in vanilla essence and sugar proved to be the most attractive for the piglets, in which the piglets interacted 459 times, about $8.1 \%$ of the total observation time. Piglets spent most of the time lying (52.4\%) and the least observed behavior was eating (18.2\%).

The percentages of piglet interaction with the different ropes are shown in Table 2. It was verified that the greatest percentage of interactions (63.6\%) was with the SV rope, probably due to the sweet taste of the rope. The PR rope aroused curiosity in the piglets, with a percentage of observations of $21.4 \%$. The SC rope was the least wanted, probably due to the bitter taste, being $15 \%$ of the time spent interacting with this rope.

\section{Discussion}

The animals should express the natural behaviors of the species, this is a basic concept that refers to welfare, for pigs the normal habits are rooting, nibbling, and exploring the environment around them. Once the animal is confined, these behaviors are reduced, so the need for enrichment objects are indispensable (Coutinho et al 2014; Foppa et al 2014; Johnson et al 2019; Padilha-Boareto et al 2020).

In the present study, it was observed that there was a greater preference for piglets for the rope soaked with vanilla essence and sugar. A possible justification for this result would be the fact that this rope is the most palatable for piglets since piglets prefer sweeter flavors (Chen et al 2020). Swine are animals with an extremely sensitive taste sense and have approximately 19,000 taste buds, a number three times greater than humans (Hellekant and Danilova 1999). According to Hellekant and Danilova (1999), there is a positive correlation between the number of papillae and the ability to taste, in this sense, pigs are more effective in feeling the taste compared to humans.

Table 1 Observations of nursey piglet behavior in relation to the presence of pure sisal ropes, vanilla essence and sugar or coffee.

\begin{tabular}{lll}
\hline & Behavior & \\
\cline { 2 - 3 } Variables & Observations & Observations \\
number & percentages (\%) \\
\hline $\mathrm{PR}^{1}$ & 154 & $2.7 \%$ \\
$\mathrm{SV}^{2}$ & 459 & $8.1 \%$ \\
$\mathrm{SC}^{3}$ & 108 & $1.9 \%$ \\
Eating & 1056 & $18.6 \%$ \\
Drinking & 11 & $0.2 \%$ \\
Urinating & 15 & $0.3 \%$ \\
Defecating & 21 & $0.4 \%$ \\
Laying down & 2969 & $52.4 \%$ \\
Standing & 221 & $3.9 \%$ \\
Playful & 294 & $5.2 \%$ \\
Others & 355 & $6.3 \%$ \\
Total & 5663 & $100.0 \%$ \\
\hline
\end{tabular}

${ }^{1} \mathrm{PR}$ : pure rope no flavor, ${ }^{2} \mathrm{SV}$ : rope soaked on vanilla essence and sugar; ${ }^{3} \mathrm{SC}$ : rope soaked on coffee

Besides, pigs have a great capacity to differentiate flavors (Foppa et al 2014), for this reason, the initial diets in the nursery phase tend to have dairy compounds and flavoring substances in their composition (Jacela et al 2010; Chen et al 2020). The preference of piglets for the rope with vanilla essence and sugar shows that is a possibility to use other objects for environmental enrichment with this flavor that can easier attract the piglets and, hence, will be more efficient in distracting the animals, consequently improving the welfare of these animals.

The coffee-soaked rope was barely accepted, probably due to its bitter taste. Studies with detection of tastes by pigs have shown that pigs did not have preferences for bitter tastes, such as coffee (Kare et al 1965; Kennedy and Baldwin 1972; 
Nelson and Sanregret 1997; Roura et al 2011; Roura and Fu 2017).

According to Foppa et al (2018), piglets are extremely intelligent and curious, so the choice of piglets for the pure rope was due to curiosity about the enrichment object. But, since when they found that it had no attractive flavor, the piglets stopped interacting with the rope, which corroborates with the finding by Trickett et al (2009), which shows that piglets lose interest in an object within a short time.

Among the other behaviors observed during the evaluation, the piglets' behavior of laying and eating was the most observed (52.4\% and $18.6 \%$, respectively). One of the most important factors that may affect behavior and welfare is the environment in which piglets are maintained (Nasirahmadi et al 2015), and through the observation of behavior, it is possible to assess its state concerning its environment, and this can help humans to promote animal welfare (Broom 1991).

So, the results of other behaviors may be related to the interaction of piglets with the ropes, because while some animals were interacting with the ropes, others were sleeping, lying down, or expressing other behaviors. According to Viana (2013), the environment can be the main modifier of pig behavior.

Table 2 Nursey piglet interaction with each type of rope.

\begin{tabular}{lcccc}
\hline & & \multicolumn{3}{c}{ Ropes } \\
\cline { 3 - 4 } & & $\mathrm{PR}^{1}$ & $\mathrm{SV}^{2}$ & $\mathrm{SC}^{3}$ \\
\hline \multirow{2}{*}{ Piglets interaction per rope } & $\mathrm{N}^{\circ}$ of observations & $154 \pm 5.5^{\mathrm{b}}$ & $459 \pm 8.9^{\mathrm{a}}$ & $108 \pm 4.9^{\mathrm{b}}$ \\
& $\%$ of observations & $21.4 \pm 0.76^{\mathrm{b}}$ & $63.6 \pm 1.25^{\mathrm{a}}$ & $15.0 \pm 0.69^{\mathrm{b}}$ \\
\hline
\end{tabular}

${ }^{1} \mathrm{PR}$ : pure rope no flavor, ${ }^{2} \mathrm{SV}$ : rope soaked on vanilla essence and sugar; ${ }^{3} \mathrm{SC}$ : rope soaked on coffee. Different letters on the same line denote a significant difference by the Tukey test $(P<0.05)$.

\section{Conclusions}

The use of equipment flavored with sweet vanilla taste is promising as a means of environmental enrichment, being more interesting to piglets. However, further studies are needed to correlate the time spent by piglets interacting with the ropes and the time they stopped consuming the diet, resulting in a possible drop in performance.

\section{Conflict of Interest}

The authors declare no conflict of interest.

\section{Funding}

This study was financed in part by the Coordination of Improvement of Higher-Level Personnel - Brazil (CAPES) Finance Code 001, and Fundação de Amparo à Pesquisa do Estado de São Paulo (FAPESP), grants 2019/17453-4, 2019/19720-0, and 2020/05316-0.

\section{References}

Bezerra BMO, Silva SSC, Oliveira AMA, Silva CVO, Parente RA, Andrade TS, Evangelista JNB, Pinheiro DCSN (2019) Avaliação do estresse e do desempenho de suínos na fase de creche, empregandose técnicas de enriquecimento Ambiental. Arquivo Brasileiro de Medicina Veterinária e Zootecnia 71:281-290.

Broom DM (1991) Animal welfare: concepts and measurement. Journal of Animal Science 69:4167-4175.

Chen J, Lei Y, Zhang Y, He S, Liu L, Dong X (2020) Beyon sweetness: the high-intensity sweeteners and farm animals. Animal

$$
\begin{array}{lll}
\text { Feed } & \text { Science } \quad \text { and } & \text { Technology. }
\end{array}
$$

Coutinho GS, Magalhães PCM, Formigoni AS, Valle G R, Moreira AH (2014) Conforto térmico e manejo de suínos na maternidade levando em consideração o bem-estar animal. Revista Eletrônica Nutritime 11: 3109-3119.

Duengelhoef M (2010) Aditivos sensoriais. In: Vieira SL (ed) Consumo e preferência alimentar dos animais domésticos. Londrina, pp 290-315.

FAO, Food and Agriculture Organization of the United Nations (2019) FAO Agri-Environmental Indicators Update: Livestock. http://www.fao.org/economic/ess/environment/data/livestockpatterns/en/. Accessed on: June 28, 2020

FASS, Federation of Animal Science Societies (2010) Guide for the care and use

of agricultural animals in research and teaching. 3rd ed. Champaign (IL): FASS. http://www.fass.org. Accessed on: January 28, 2019.

Foppa L, Caldara FR, Machado SP, Moura R, Santos RKS, Nääs IA, Garcia RG (2014) Enriquecimento Ambiental e Comportamento De Suínos: Revisão. Brazilian Journal of Biosystems Engineering 8:0107.

Foppa L, Caldara FR, Moura R, Machado SP, Nããs IA, Garcia RG, Gonlçalves LMP, Oliveira GF (2018) Pig's behavioral response in nursery and growth phases to environmental enrichment objects. Spanish Journal of Agricultural Research. doi: $10.5424 /$ sjar/2018163-12303

Hellekant G, Danilova V (1999) Taste in domestic pig, Sus scrofa. Journal of Animal. Physiology and Animal Nutrition 82:8-24.

Jacela JY, DeRouchey JM, Tokach MD, Goodband RD, Nelssen JL, Renter DG, Dritz SS (2010) Feed additives for swine: Fact sheets flavors and mold inhibitors, mycotoxin binders, and antioxidants. Journal of Swine Health and Production 18:27-32. 
Zimmerman JJ, Karriker LA, Ramirez A, Schwartz KJ, Stevenson GW, Zhang J (ed) Diseases of Swine, Eleventh Edition. John Wiley \& Sons, Inc. Hoboken.

Kare MR, Pond WC, Campbell J (1965) Observations on the taste reaction in pigs. Animal Behaviour 13:265-269.

Kelly HCR, Bruce JM, English PR, Fowler VR, Edwarsd SA (2000) Behaviour of 3-week weaned pigs in Straw-Flow, deep straw and flatdeck housing systems. Applied Animal Behaviour Science 68:269-280.

Kennedy JM, Baldwin BA (1972) Taste preferences in pigs for nutritive and non-nutritive sweet solutions. Animal Behaviour 20:706-718.

Mcdonald P, Edwards RA, Greenhalgh JFD, Morgan CA, Sinclair LA, Wilkison RG (2010) Mcdonald P, Edwards RA, Greenhalgh JFD, Morgan CA, Sinclair LA, Wilkison RG (ed). In: Animal Nutrition, $7^{\text {th }}$ edn. Wiley, New York, pp. 461-477

Munro PJ, Lirette A, Anderson DM, Ju HY (2000) Effects of a new sweetener, Stevia, on performance of newly weaned pigs. Canadian Journal of Animal Science 80:529-531.

Nasirahmadi A, Richter U, Hensel O, Edwards S, Sturm B (2015) Using machine vision for investigation of changes in pig group lying patterns. Computers and Eletronics in Agriculture 119: 184-190.

Nelson SL, Sanregret JD (1997) Response of Pigs to Bitter-tasting Compounds. Oxford University Press 22:129-132.

Padilha-Boaretto JB, Groff-Urayama PM, Einsfeld SM, Souza C, Mendes AS, Maeda EM, Takahashi SE (2020) Effect of environmental enrichment for piglets in the nursery phase. AsianAustralasian Journal of Animal Sciences. doi: 10.5713/ajas.20.0222
Roura E, Fu M (2017) Taste, nutrient sensing and feed intake in pigs (130 years of research: then, now and future). Animal Feed Science and Technology 233:3-12.

Roura E, Humphrey B, Klasing K, Swart M (2011) Is the pig a good umami sensig model for humans? A comparative taste receptor study. Flavour and Fragance Journal 26:282-285.

SAS Institute Inc (2013) SAS/ACCESS ${ }^{\circledR} 9.4$ Interface. Cary, NC: SAS Institute Inc.

Sterk A, Schlegel P, Mul AJ, Ubbink-Blanksma M, Bruininx EMAM (2008) Effects of sweeteners on individual feed intake characteristics and performance in group-housed weanling pigs. Journal of Animal Science 86:2990-2997.

Scott K, Taylor L, Gill BP, Edwards SA (2006) Influence of different types of environmental enrichment on the behaviour of finishing pigs in two different housing systems: 1. Hanging toy versus rootable substrate. Applied Animal Behaviour Science 99:222-229.

Trickett SL, Guy JH, Edwards SA (2009) The role of novelty in environmental enrichment for the weaned pig. Applied Animal Behaviour Science 116:45-51.

Van de Weerd HA, Docking CM, Day JEL, Avery PJ, Edwards SA (2003) A systematic approach towards developing environmental enrichment for pigg. Applied Animal Behaviour Science 84:101-118.

Viana JM (2013) Comportamento de leitões desmamados em diferentes idades, desafiados em piscina. Theses, Universidade Federal de Viçosa.

Van de Weerd H, Ison S (2019) Providing Effective Environmental Enrichment to Pigs: How Far Have We Come? Animals. doi: 10.3390/ani9050254 